\title{
Morbidity and mortality after peritoneovenous shunt surgery for refractory ascites
}

\author{
D RUBINSTEIN, I MCINNES, AND F DUDLEY
}

From the Gastroenterology Service, Alfred Hospital, Melbourne, Australia.

SUMMARY A prospective analysis of the morbidity and mortality after peritoneovenous shunting was carried out in 25 patients who had a total of 27 shunts for refractory ascites. Major complications were limited to the patients in whom ascites was secondary to hepatic rather than peritoneal disease. Immediate postoperative complications followed 17 out of the 23 shunts carried out in patients with liver disease and included septicaemia (two), profound hypotension (two), pulmonary oedema (one), and clinically evident disseminated intravascular coagulation (14). Long term morbidity was again limited to the patients with liver disease and included chronic shunt infection (two) and major venous thrombosis (two). Shunt associated mortality was only seen in the patients with liver disease. Despite late shunt blockage in five long term survivors with alcoholic liver disease fluid retention was easily controlled by simple medical means probably because of improved liver function associated with abstinence from alcohol. It is concluded that: (1) patients with hepatic and malignant ascites respond differently to the insertion of a peritoneovenous shunt; (2) Shunt patency should be monitored regularly in patients with liver disease and, because of the potential for septic and thrombotic complications, if blocked the shunt should be removed and; (3) because of the morbidity and mortality of peritoneovenous shunt surgery in patients with liver disease and refractory ascites, an alternative mode of therapy, such as repeated ultrafiltration and reinfusion of ascitic fluid, may be a more effective initial therapeutic approach especially in patients in whom there is a reversible element to their underlying liver disease.

Peritoneovenous shunts were first reported to be useful in the treatment of refractory ascites in $1974 .^{1}$ There are a number of immediate and dramatic benefits which follow shunt insertion including increase in renal blood flow, glomerular filtration rate and renal salt and water excretion, decrease in plasma renin and aldosterone concentrations and ascites becomes controllable with a reduced or absent need for diuretics. ${ }^{23}$ Unfortunately, peritoneovenous shunt surgery has also been associated with considerable short and long term morbidity and mortality. Complications include fever, disseminated intravascular coagulation (DIC), shunt occlusion, hypokalaemia, infection, ascites leak, variceal haemorrhage, bowel obstruction, pulmonary oedema, air embolism, and pneumothorax. ${ }^{4}$ In one

Address for correspondence: Dr F J Dudley, Director, Gastroenterology Service, Alfred Hospital, Commercial Road, Prahran 3181, Melbourne. Australia.

Received for publication 12 November 1984 series of 23 patients, six died within a month of surgery and complications occurred in more than two-thirds of the patients. ${ }^{5}$ Because of these problems, the precise role of peritoneovenous shunts in the treatment of refractory ascites remains to be defined.

This study reports on shunt patency and shunt associated morbidity and mortality in a prospective short and long term follow up study of 25 patients who received 27 peritoneovenous shunts.

\section{Methods}

\section{PATIENTS}

Twenty five patients received 27 peritoneovenous (Le Veen) shunts as the definitive treatment for refractory ascites over a six year period. All patients had ascites which was resistant to therapy in hospital with bed rest, salt restriction, diuretic therapy and infusion of salt poor albumin. Patient 
non-compliance, inadvertent sodium administration and electrolyte imbalance were excluded and the ascites was considered refractory if therapy was complicated by signs of intravascular volume depletion with postural hypotension and progressive impairment of renal function in the absence of significant fluid mobilisation. In 21 patients the ascites was secondary to hepatic disease and in four it was caused by metastatic spread of carcinoma to the peritoneum. The cause of the ascites is detailed in the Table. Patients with liver disease were graded before surgery according to the clinical and biochemical criteria of Pugh. ${ }^{6}$ No patient was grade A, 12 were grade $B$, and nine were grade C. All peritoneovenous shunts were inserted by one of two surgeons.

The immediate postoperative course was reviewed closely and the patients subsequent clinical course was monitored carefully. Shunt patency was assessed following the intraperitoneal injection of technetium $99 \mathrm{~m}$ sulphur colloid ${ }^{7}$ before discharge from hospital and subsequently at irregular intervals. All patients who are currently alive had their shunt patency tested just before completion of the study.

\section{Results}

\section{EARLY MORBIDITY}

A wide range of problems complicated the patients clinical course between the time of insertion of the peritoneovenous shunt and their discharge from hospital. Five shunts failed to function in the immediate postoperative period. This occurred predominantly in the earlier cases in the series and was largely related to malposition of the venous end of the shunt. Reoperation usually proved necessary to establish flow and this problem has been overcome with surgical experience. Other complications developed only in the patients with liver disease as a cause of their ascites. These 21 patients received a total of 23 shunts and immeditate postoperative complications occurred in $17(74 \%)$. In all, the

Table Cause of ascites in patient population

\begin{tabular}{lrlr}
\hline Hepatic $(n=21)$ & & $\begin{array}{l}\text { Malignant }(N=4) \\
\text { (Primary site) }\end{array}$ \\
\hline Budd Chiari & 2 & Colon & 1 \\
CAH $^{*}$ autoimmune $\dagger$ & 1 & Breast & 1 \\
CAH* B & 1 & Stomach & 1 \\
Haemochromatosis $\dagger$ & 1 & Pancreas & 1 \\
Alcoholic liver disease $\dagger$ & 14 & & \\
Myelofibrosis & 2 & & \\
\hline
\end{tabular}

* chronic active hepatitis

t one patient had complicating carcinoma of liver or bile duct complication was of major clinical import and contributed to the deaths of eight patients. One patient developed pulmonary oedema. Two patients developed profound hypotension in the absence of sepsis. Both patients responded to a period of inotropic support with dopamine which was slowly withdrawn over two to three days as the patients condition stabilised. Two patients developed septicaemia despite a diagnostic paracentesis having demonstrated sterile ascites 48 hours before shunt insertion. Finally 14 patients developed clinically evident DIC and shunt ligation was necessary to control bleeding in four of these patients.

\section{LATE MORBIDITY}

No shunt associated morbidity was encountered in the long term follow up of the four patients in whom surgery was undertaken for malignant ascites. In all patients in whom the shunt remained patent the ascites was easily controlled.

Among the 13 patients with ascites complicating liver disease who were discharged from hospital after 15 peritoneovenous shunts there was considerable long term morbidity. Two patients developed a chronic shunt infection, one of whom had an associated glomerulonephritis which resolved on shunt removal and the other died of staphylococcal septicaemia after self-withdrawal of long term antibiotic therapy. Two patients developed major venous thrombosis adjacent to the site of insertion of the venous arm of the shunt, one of the right brachiocephalic vein and the other of the superior vena cava.

\section{SHUNT BLOCKAGE}

All patients with malignant ascites were discharged from hospital with a functioning shunt. In two the valve subsequently blocked and required replacement. Thirteen of the patients with liver disease were discharged from hospital on 15 separate occasions after insertion of a peritoneovenous shunt. In 14 the shunt was working at the time of discharge and in 11 of these has subsequently spontaneously blocked. Generally the blockage occurred in the valve or in the venous limb of the shunt. There are currently six surviving patients some seven to 54 months after shunt insertion. Five of these patients, all with alcoholic liver disease, have either had their shunts removed or they are known to be blocked. Despite this all five long term survivors with non-functioning shunts are on little or no diuretic therapy and ascites is not a clinical problem.

MORTALITY

There was no shunt associated mortality in any of 
the four patients with malignant ascites but all these patients died within three months of shunt insertion as a result of widespread malignancy. Of the 21 patients with liver disease eight died during the admission in which their shunt was inserted and in all cases shunt related complications contributed to their death. Seven other patients have subsequently died within a year of shunt insertion. Death was usually related to the underlying liver disease or complicating malignancy but, in three, late complications associated with the shunt were contributing factors.

Cumulative survival curves have been calculated from life table analysis on the 21 patients who underwent peritoneovenous shunt surgery for the treatment of liver disease complicated by refractory ascites. Early mortality is obviously high and the survival curve plateaus at approximately 12 months (Figure).

\section{Discussion}

This study has shown that peritoneovenous shunt surgery for refractory ascites can be associated with considerable morbidity in both the short and long term and that shunt related complications often contribute to mortality. Although these results are consistent with some of the published data, ${ }^{58}$ it is in marked contrast with other more favourable reports. ${ }^{9} 10$

Major complications were limited to the patient group in whom ascites was secondary to hepatic rather than peritoneal disease. All the patients with malignant ascites had an uncomplicated postoperative course with good control of their ascites and this is consistent with other studies on the use of peritoneovenous shunts in such patients. ${ }^{11}{ }^{12} \mathrm{~Pa}$ -

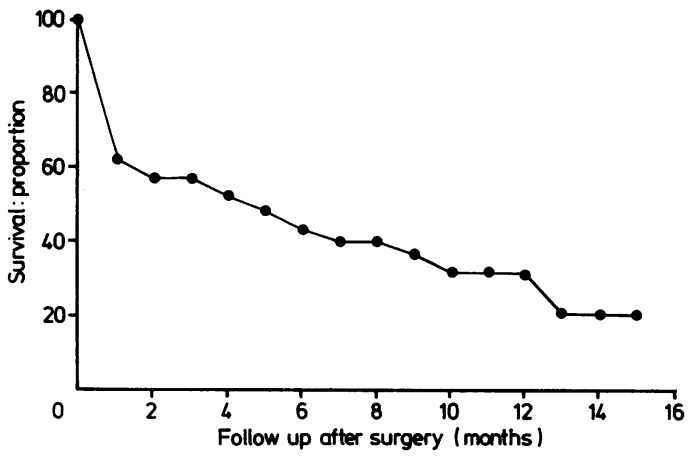

Figure Cumulative survival curve for patients undergoing peritoneovenous shunt surgery for the treatment of refractory ascites complicating liver disease. tients with malignant ascites secondary to carcinoma of the breast or ovary have a relatively good prognosis compared with other forms of peritoneal malignancy ${ }^{12}$ and they should receive the greatest benefit from peritoneovenous shunt surgery.

In contrast the postoperative course of the patients with ascites secondary to liver disease was notable for the number of serious complications. Clinical DIC was only seen in this group. Laboratory evidence of DIC can complicate peritoneovenous shunt surgery in patients with both hepatic ${ }^{13}$ and malignant ascites ${ }^{11}$ although it is rarely clinically evident in the latter group. ${ }^{11} 12$ Independent of aetiology, ascites has been shown to contain collagen with the ability to activate both platelets and Factor X, both of which will tend to initiate DIC. ${ }^{14}$ There are a number of reasons why patients with hepatic ascites may be more susceptible to clinical DIC after peritoneovenous shunts than patients with malignant ascites. ${ }^{4}$ Patients with liver disease often have laboratory evidence of impaired haemostasis before surgery and poor hepatic function prevents them responding adequately to the increased synthetic demands imposed by the rapid consumption of clotting factors. They also often have low levels of antithrombin III, a naturally occurring coagulation inhibitor and their ability to remove activated clotting factors may also be compromised.

Sepsis was a major cause of morbidity and mortality after peritoneovenous shunt surgery in this and other studies. ${ }^{516}$ To prevent this complication it is important to definitively exclude spontaneous bacterial peritonitis by appropriate ascitic fluid analysis on the day of surgery. When shunt infection does occur, however, it cannot be eradicated by prolonged antibiotic therapy and complications of chronic sepsis such as glomerulonephritis ${ }^{17} 18$ may develop. Once infection has been documented the shunt should be removed. ${ }^{16}$

A complication not previously reported but seen in the immediate postoperative period in two of the patients in this series was profound non-septic hypotension. The pathogenesis of this complication remains obscure but implies the presence of some vasoactive substance, possibly endotoxin, ${ }^{19}$ in the ascitic fluid of some patients with liver disease capable of producing marked circulatory collapse.

There was a high rate of spontaneous shunt blockage in both the malignant and hepatic patient groups. Although ascites was refractory to medical therapy preoperatively the long term survivors with blocked shunts required minimal or no diuretic therapy. All had active decompensated alcoholic liver disease at the time of shunt surgery but they subsequently abstained from or reduced their alco- 
hol intake with slow but steady improvement in their clinical status and liver function. These findings indicate that the absence of ascites does not imply shunt patency and emphasises the need for regular dynamic assessment of shunt flow. Because of the potential for septic and thrombotic complications the shunts should be removed if shown to be non functioning.

Two groups of patients with liver disease and refractory ascites were evident in this study. One group had inactive end stage or progressive liver disease which was not amenable to currently available therapy and their prognosis was poor. The other group, although presenting with decompensated liver disease, had active liver cell damage with the potential for partial reversibility if the activity could be controlled. Their refractory ascites could thus be considered temporary. In both groups the need for peritoneovenous shunting is only short term and all could thus be considered suitable for intermittent ultrafiltration and reinfusion of ascitic fluid, ${ }^{2021}$ a procedure with apparently less acute morbidity and mortality and obviously none of the long term morbidity of the peritoneovenous shunt. Certainly such a comparison should be worthy of controlled study.

\section{References}

1 Le Veen HH, Christoudias G, Moon JP, Luft R, Falk $\mathrm{G}$, Grosberg S. Peritoneo-venous shunting for ascites. Ann Surg 1974; 180: 580-91.

2 Blendis LM, Greig PD, Langer B, Baigrie RS, Ruse J, Taylor BR. The renal and hemodynamic effects of the peritoneovenous shunt for intractable hepatic ascites. Gastroenterology 1979; 77: 250-7.

3 Greig PD, Blendis LM, Langer B, Taylor BR, Colapinto RF. Renal and hemodynamic effects of the peritoneovenous shunt. II: Long term effects. Gastroenterology 1981; 80: 119-25.

4 Epstein M. Role of the peritoneovenous shunt in the management of ascites and the hepatorenal syndrome. In: Epstein M. ed. The kidney in liver disease. New York, Amsterdam, Oxford: Elsevier Biomedical, 1983; 583-600.

5 Greig PD, Langer B, Blendis LM, Taylor BR, Glynn MFX. Complications after peritoneovenous shunting for ascites. Am J Surg 1980; 139: 125-31.
6 Pugh RNH, Murray-Lyon IM, Dawson JL, Pietroni MC, Williams R. Transection of the oesophagus for bleeding oesophageal varices. Br J Surg 1973; 60: 646-9.

7 Krichmer N, Hart J. Radionuclide assessment of Le Veen shunt patency. Ann Surg 1977; 185: 145-6.

8 Fry PD, Hallgren R, Robertson ME. Current status of the peritoneovenous shunt for the management of intractable ascites. Can J Surg 1979; 22: 557-9.

9 Le Veen HH, Wapnick S, Grosberg S, Kinney MJ. Further experience with peritoneo-venous shunt for ascites. Ann Surg 1976; 184: 574-9.

10 Wapnick S, Grosberg S, Kinney M, Le Veen HH. LeVeen continuous peritoneal-jugular shunt. Improvement of renal function in ascitic patients. JAMA 1977; 237: 131-3.

11 Reinhold RB, Lokich JJ, Tomashefski J, Costello P. Management of malignant ascites with peritoneovenous shunting. Am J Surg 1983; 145: 455-7.

12 Souter RG, Tarin D, Kettlewell MGW. Peritoneovenous shunts in the management of malignant ascites. Br J Surg 1983; 70: 478-81.

13 Harmon DC, Demirjian Z, Ellman L, Fischer JE. Disseminated intravascular coagulation with the peritoneovenous shunt. Ann Intern Med 1979; 90: 774-6.

14 Salem HH, Koutts J, Handley C, Van der Weyden MB, Dudley FJ, Firkin BG. The aggregation of human platelets by ascitic fluid: A possible mechanism for disseminated intravascular coagulation complicating Le Veen shunts. Am J Haematol 1981; 11: 153-7.

15 Salem HH, Dudley FJ, Merrett A, Perkin J, Firkin BG. Coagulopathy of peritoneovenous shunts: studies on the pathogenic role of ascitic fluid collagen and value of antiplatelet therapy. Gut $1983 ; 24$ : 412-7.

16 Wormser GP, Hubbard RC. Peritonitis in cirrhotic patients with Le Veen shunts. Am J Med 1981; 71: 358-62.

17 Boulton-Jones JM, Sissons JGP, Evans DJ, Peters DK. Renal lesions of subacute infective endocarditis. $\mathrm{Br}$ Med J 1974; 2: 11-14.

18 Black JA, Challacombe DM, Ockenden RG. Nephrotic syndrome associated with bacteraemia after shunt operations for hydrocephalus. Lancet $1965 ; 2$ : 921-4.

19 Tarao K, So K, Moroi T, Ikevchi T, et al. Detection of endotoxin in plasma and ascitic fluid of patients with cirrhosis: its clinical significance. Gastroenterology 1977; 73: 539-42.

20 Levy VG, Opolon P, Pauleau N, Caroli J. Treatment of ascites by reinfusion of concentrated peritoneal fluid. Review of 318 procedures in 210 patients. Postgrad Med J 1975; 51: 564-6.

21 Villeneuve JP, Thuot C, Marleau D, Joly JG, Huet PM, Viallet A. Treatment of resistant ascites by continuous ultrafiltration-reinfusion of ascitic fluid. Can Med Assoc J 1977; 117: 1296-8. 